\title{
Cost Power Curtailment Analysis for Optimum PV Size and the Energy Potential for the Desalination Plant on the Island Distribution System
}

\author{
Cheng-Ting Hsu, Roman Korimara, Tsun-Jen Cheng, Lian-Jou Tsai, and Hung-Ming Huang
}

\begin{abstract}
This paper proposes a power curtailment strategy that limits the injected current on the grid-line with the voltage control scheme for optimal PV sizing of PV system according to the provided temperature and solar irradiation in an island-scale distribution system. The proposed voltage control approach is applied to remove above-limit injected $P V$ power to sustain voltage variation ratio within the required limits. When this scheme applied on different size of PV projects although there is a drawback on the increased PV rejection, the optimum $P V$ size can be determined on the maximum net present value (NPV) of the PV project. It is found that all year round on the selected island scale distribution system the rejected PV generation of the optimum PV capacity accounts much better for used on the island desalination plant than not used. Thus a better utilization of solar energy can be enhanced.
\end{abstract}

Index Terms-Photovoltaic, net present value, annual curtailed and non-curtailed photovoltaic generation.

\section{INTRODUCTION}

Sustaining the voltage variation at the installation site of any renewable energy technology due to its injected power hikes is a major concern when to take into consideration the power system stability. These unfavorable power hikes are referred to as renewable technology intermittent power output which is an uncontrollable parameter. An active power curtailment strategy is applied to curtail the generation above the required limits. In this strategy, a voltage control algorithm for PV systems, which is included in the advance distribution automation system (ADAS), is considered. Although partial generation must be curtailed during peak solar irradiation in a feeder with high PV penetration, the investment of PV system may still be justifiable given the total solar energy harvested over the system life cycle.

Furthermore, when the installed PV capacity increases the $\mathrm{PV}$ penetration increases as well so with severe PV penetration not only causes the reverse power flow but also violates the strict definition of DG based on the voltage level to which the DG is connected. In this paper, a strict definition of DG based on the voltage level used is $\pm 5 \%$ [1]. It emphasized overvoltage is problematic in the distribution feeder when numerous PV systems installed [2]-[4]. Many positive research findings have been published that proving

Manuscript received October 10, 2015; revised February 23, 2016. This work was supported in part by the National Science Council under the Contract MOST (104-3113-E-214-002).

The authors are with the Southern Taiwan University of Science and Technology, No.1 Nan-Tai Street, Tainan, Taiwan (e-mail: cthsu@ stust.edu.tw, da220203@stust.edu.tw, chengtj@stust.edu.tw). some techniques which are able to diminish this over voltage problem. A reactive power STATCOM and OLTCs (on load tap changing transformer) can be applied for voltage flicker improvement and reactive power management respectively [5]-[7]. And a hybrid photovoltaic and a battery storage system have also been proposed for the demand side application. Energy storage is highly needed to compensate the uncertainty in renewable power output in order to improve quality of power supply [8], [9]. It is claimed that Lithium-iron phosphate $\left(\mathrm{LiFePO}_{4}\right)$ battery has a long operating lifetime and is environment friendly. Also the technique of active power curtailment is proposed for increasing installed PV capacity and energy yield [10], [11].

The need to make more energy available at affordable prices to enable people to use modern energy is the main challenge in the developing world. Fortunately, having the favorable position of small islands on the equator, some countries have the advantages of developing application of several types of renewable energy such as tidal energy, wind energy and solar energy etc. Renewable energy source also represents one promising option for considerable energy needs of desalination processes. Thus a solar powered desalination plant is used to supply water up to 16 liter in the United Arab Emirate with the electricity consumption of $44 \mathrm{kWh}$ enough to transform desert into a green haven [12]. While Kiribati is actually a tiny atoll island with the population of more than one hundred thousand; a photovoltaic panel may be a good solution for fulfilling the energy requirement and protecting the environment. In the context of energy sustainability, storing the rejected PV generation to drive the desalination plant is practically viable. However further analysis to justify the PV powered desalination plant investment on the island is needed because it is beyond the scope of this paper.

This paper is organized as follows. First Section II presents the problem formulation of this research paper and followed by the problem methodology and voltage control scheme in Section III. In Section IV, it presents the proposed methodology followed by the case study analysis in Sections $\mathrm{V}$ and VI. Section VII presents the conclusion and followed by references.

\section{PROBLEM FORMULATION}

The objective is to enhance the optimal PV, taken into account the installation capacity $\mathrm{j}$, by maximizing the cost function of NPV while satisfying both the equality and inequality constraints further describe as: 
A. Objective: To Enhance the Optimal PV Capacity by Maximizing the NPV Cost Function

$$
\operatorname{NPV}\left(P_{j}^{n c s d}, P_{j}^{n c c d}\right)=-C_{C I}+\mathrm{CF}_{i}
$$

where the power output of PV capacity $j: P_{j}^{n c s d}$ and $P_{j}^{n c c d}$ are the active power with and without curtailment respectively. Also $C_{C I}$ is the capital investment of the $\mathrm{PV}, \mathrm{CF}_{i}$ is the net cash inflow for year $i$. And it can be expressed as

$$
\begin{aligned}
& \mathrm{CF}_{i}=\mathrm{FIT} \sum_{i=1}^{N} \operatorname{PWF}^{i}\left(\mathrm{NSD}_{y r} P_{j}^{n c s d}+\mathrm{NCD}_{y r} P_{j}^{n c c d}\right) \\
& (1-d r)^{i}-C_{o \& m, i}(1-g)^{i}
\end{aligned}
$$

Subjects to:

$$
P_{j}^{n c s d}, P_{j}^{n c c d}=\sum_{j=1}^{J} \sum_{h=1}^{24} P_{h . j}
$$

$P_{h, j}$ is the hourly power output of PV capacity, $j$. And $P_{\text {map }}$ is the PV maximum allowable power.

$$
P_{h, j}=\left\{\begin{array}{l}
P_{\text {map }} \text { if } P_{h, j} \geq P_{\text {map }} \\
P_{h, j} \text { otherwise }
\end{array}\right.
$$

where FIT, $P W F^{i}, d r, C_{o \& m, i}, g$ are the feed in tariff, present worth factor, PV's performance derating factor, maintenance cost and inflation rate at year, $i$, respectively.

\section{B. Constraints}

Generation constraints: The output of all the generations must satisfy the daily demand. This is known to be the equality constraints

$$
\sum_{g=1}^{N} P_{g}+P_{j, k}=P_{L}
$$

where $P_{L}$ is the total demand whilst the $P g$ and $P j$ are generators and attached $\mathrm{PV}$ runs on the capacity $j$ respectively.

PV active power curtailment constraint: This power curtailment is the inequality constraint. The PV output must not exceed the allowed maximum power injected into the grid-line.

$$
P_{j, k}\left(T_{s}, G\right) \leq P_{\text {map }}
$$

where $P_{j, k}\left(T_{s}, G\right)$ is the mathematical model developed by [13] to estimate the output power of PV for capacity, $j . P_{j, k}\left(T_{s}, G\right)$ can be further expressed as

$$
P_{j, k}\left(T_{s}, G\right)=-1.15 \times 10^{4}+909 G+754 T_{s}-2 G T_{s}(W)
$$

While the surface temperature $\left(T_{s}\right)$ of the PV panel is calculated as

$$
T_{s}(G)=0.903+0.001 G-1.39 \times 10^{7} G^{2}\left({ }^{\circ} C\right)
$$

Voltage constraints: The voltage level at every bus is an inequality constraint. The voltage level at the installation site must be within the specified limits.

$$
V_{k}^{\min } \leq V V R_{k} \leq V_{k}^{\max }
$$

$V V R_{k}$ can be further expressed as

$$
V V R_{k}=\frac{V_{k}^{P V}-V_{k}}{V_{k}} \times 100 \%
$$

where $V_{k}^{\min }$ and $V_{k}^{\text {max }}$ are the minimum and maximum voltage level at bus $k$ respectively. Also $V_{k}^{P V}$ and $V_{k}$ are the voltage level with PV and without PV respectively.

Penetration constraints: The penetration level is an inequality constraint. With the PV the penetration level at installation site must be less than and equal to the specified upper limit.

$$
P L_{k} \leq P L_{k}^{\mathrm{map}}
$$

where the $P L_{k}{ }^{\text {map }}$ is the specified upper PV penetration limit at bus $k$, whilst $P L_{k}$ is the penetration level also at bus $k$ and it can be computed by (12) as

$$
P L_{k}=\frac{\sum_{i} P_{p v}^{i}}{P_{\text {total }}} \times 100 \%
$$

where $P_{p v}{ }^{i}$ is the rating capacity of the $i$-th $\mathrm{PV}$ and $P_{\text {total }}$ is the total power delivered to the load.

If any of the above condition is violated, the solution obtained is not feasible which means the test network was suffered by a power quality problem. In the case of increasing the $P_{j}$ i.e. the installed PV capacity, $j$, it will obviously violates condition stated in (9-12), so this paper has proposed the power curtailment strategy to maintain the well operating of the test network within a specified limits. In order to achieve the goal of power curtailment strategy, a voltage control scheme was adopted in this paper and it is further described as below.

\section{Voltage Control Scheme Algorithms}

This scheme algorithm is embedded inside the inverter and acted against any over-voltage problems especially when large DG connects to the grid-line. The aforementioned scheme is further described in the flowchart below.

The voltage control scheme is applied to prevent the over voltage problem in the distribution feeder. Injected large PV generation is causing the current to overtopping the maximum allowed limits and results in overvoltage triggering the PV inverter setting. To avoid the tripping of the PV system it can be done by shifting the operating point of the PV system from MPPT algorithm. The proposed algorithm has shown in Fig. 1. 
It clearly shows that if the output power of the PV system exceeds the maximum limit, the algorithm is then executed to remove the excessive part or otherwise it is good to go.

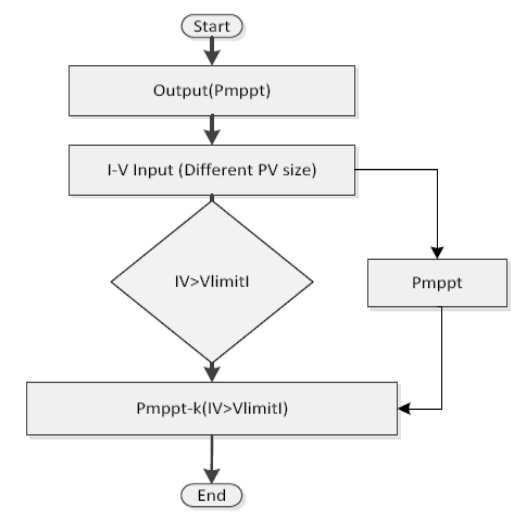

Fig. 1. Voltage control algorithm of active PV power generation curtailment.

\section{EXPERIMENTAL PROCEDURE TO DETERMINE THE OPTIMUM PV SIZE}

In this study, the load flow analysis is applied to solve system voltage according to the hourly feeder loading and solar irradiation. A range of PV capacities up to $2.8 \mathrm{MW}$ have been tested and analyzed to estimate how much energy yielded and rejected to satisfy the constraints. In the analysis the constraints of voltage variation ratio and penetration level were observed with respect to the hourly feeder loading and solar irradiation. Exceeding the found allowable power by installing the outsized PV system at the installation site will violate the system voltage constraints and lead to severe penetration impact. The cost benefit analysis is also performed by using the annual amount of absorbed energy into the grid-line from different PV capacities to determine the optimal PV capacity.

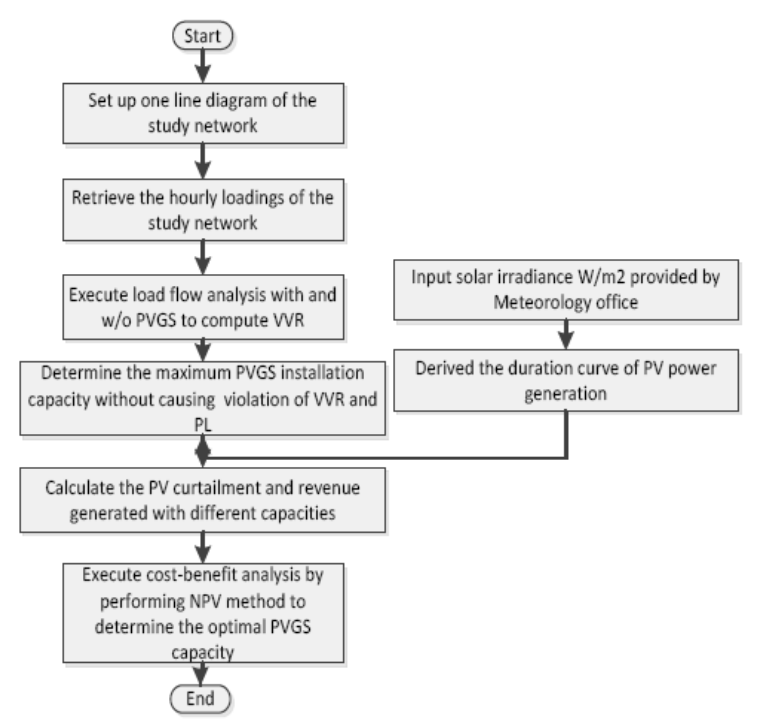

Fig. 2. Flowchart of determining the optimum PV size at bus $k$.

Fig. 2 shows the flowchart of the proposed methodology. It is further described as the following steps.

Step 1: Prepare the study system configuration and data for load flow analysis. The study network configuration should be identified for preparing a one-line diagram. The line segment attributes such as conductor size and length and distribution transformer capacity and impedance are also collected at the same time. It is also necessary to retrieve the hourly power generation and loading of the study system.

Step 2: Take a 24-hours load flow analysis with and without considering the installation of $\mathrm{PV}$ to find the maximum allowable installation capacity at the proposed installation site. The output power of PV is assumed to its peak rating capacity during the load flow analysis. The simulation results for the voltage at all buses and power generation of each generation unit must be examined for not violating the limits. In this paper, all the buses voltage should be controlled within $0.95-1.05 \mathrm{p} . \mathrm{u}$ and the generator output power should be operated within 0.3-1.0 times of its rating capacity.In addition, the allowable voltage variation ratio $(V V R)$ at all buses is limited within $\pm 5 \%$ to ensure the power quality. The $V V R_{k}$ can be solved by (9-10) to determine the maximum allowed PV injection power at bus $\mathrm{k}$ and it will be the system condition indicator when any PV size introduced into the grid-line.

Step 3: Estimate the power generation of PV. To make the analysis reasonable and able to be used in general case for varying solar irradiance condition, it is necessary to find out the mathematical model of the PV. In this paper, the PV model (7-8) is obtained and verified by the actual system which has been installed at the Kaohsiung World Games Stadium in Taiwan [13]. In this step, the model was used to derive the estimated output power for different PV capacity, $j$, according to the hourly solar irradiation.

Step 4: Derive the output generation from different PV capacities to run on a $24 \mathrm{hrs}$ load flow analysis to observe the hourly voltage variation ratio. And a power curtailment strategy is applied when voltage constraints was violated. This means partial PV generation has to be rejected or curtailed to maintain the system voltage operation limit as well as the system penetration limit. The total $24 \mathrm{hrs}$ PV allowed into the feeder is then used to calculate the yearly revenue generated by the PV system.

Step 5: Perform the cost effectiveness analysis by adopting the NPV method to be discussed below. The total PV energy allowed into the study feeder is then used to calculate the yearly revenue by PV system. Add in this yearly revenue generated from different PV capacities, $j$, into (1) and the NPV can then be solved accordingly. The NPV of an investment is the sum of the present values of all cash flows such as capital investment and revenue generated by PV system over its entire lifetime.

Any project is considered to be financially feasible only if the corresponding NPV is positive. The PBY is also solved to figure out how many years each installed PV capacity can pay back its initial capital investment cost from its yearly generated revenue for further analysis. By setting the NPV to zero, the PBY can then be solved.

\section{Case Study-Electrical Power System Simulation}

\section{A. Power System Configuration of the Test Network}

To determine how large the PV projects can be put into effect at the proposed installation site without violating the voltage limits, a large scale PV installed at PUB DNST in 
Kiribati was selected as a case study for a computer simulation. A financial analysis is also performed in the last section of this paper to justify whether this PV project investment is financially viable.

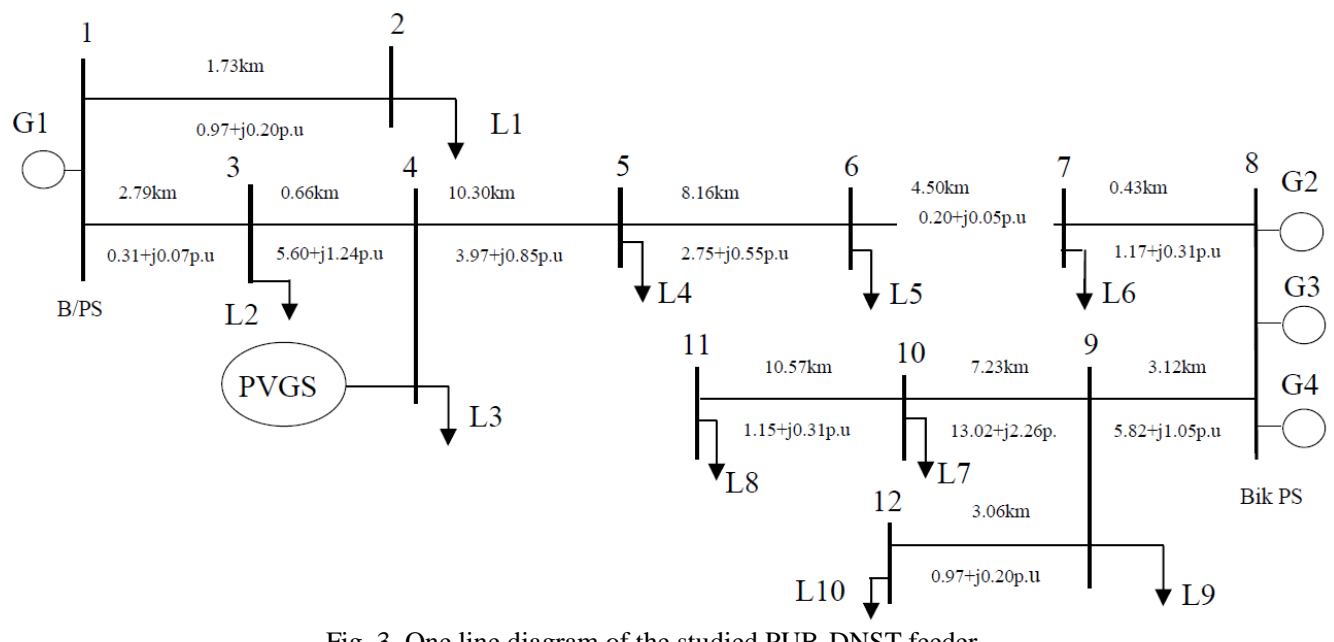

Fig. 3. One line diagram of the studied PUB-DNST feeder.

Fig. 3 shows the one-line diagram of the power system in Kiribati. The large scale PV is assumed to be installed at bus 4 . There is one diesel generator at Betio (bus 1) with available capacity of $1200 \mathrm{~kW}$, and three diesel generators at Bikenibeu (bus 8) with available capacities of $1350 \mathrm{~kW}$ each, which provide a base load at a specific fuel consumption of 0.25 litre $/ \mathrm{kWh}$. The rating generators output voltage are $11 \mathrm{kV}$ with an operating frequency of $50 \mathrm{~Hz}$. Approximately 60 underground cables with various types are used in distributing $11 \mathrm{kV}$ network around the island. There are 59 transformers in service, which are $11 \mathrm{kV} / 415 \mathrm{~V}$ step down transformers with rated capacity of 50, 100, 200 and $750 \mathrm{kVA}$.

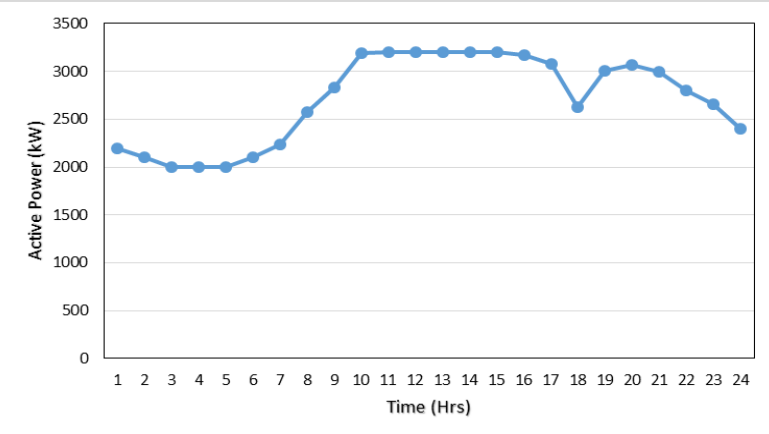

Fig. 4. Typical daily load demand profile.

Fig. 4 shows a typical daily load profile that recorded on South Tarawa. It shows basically two insights: firstly the peak load is $3.2 \mathrm{MW}$, which occurred at $11 \mathrm{hrs}$ and $13 \mathrm{hrs}$; secondly the off peak load is $2 \mathrm{MW}$, which occurred from $5 \mathrm{hrs}$ to $6 \mathrm{hrs}$. It also shows that the high power consumption on the island occurs significantly during working and business hours. In order to simplify the process of determining the annual load demand, it is assumed that all days throughout the year have the same load demands as shown in Fig. 4. The profile shows that the loading occurs during daytime, which implies that the power generation by the PV system can effectively offset the bus 4 feeder loading.

Based on the PUB DNST network topology and hourly loading, the load flow simulation results in Fig. 5 shows the voltage profile of the buses while regulating the voltage at G2-4 and G1 to 1.03p.u. and 1.0p.u. respectively. It is found that the voltage varied between $0.956 \mathrm{p}$.u. to $1.03 \mathrm{p}$.u. in normal condition. It satisfies the voltage operation limits for providing good power quality to customers.

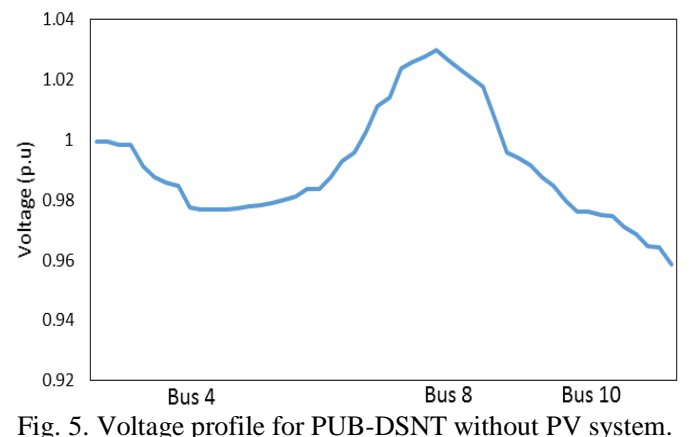

\section{B. Power System Analysis with Considering Different PV Sizes}

Introducing the PV to the existing network may alter the voltage level at installation site and nearby buses. In order to make sure the voltage level, at all buses, remains at the required limits, the maximum allowed PV installation capacity will be determined. After applying the load flow analysis with different PV sizes applied, it is found that the maximum allowable power at bus 4 is $690 \mathrm{~kW}$ which corresponds to the penetration level of $22 \%$ as shown in Fig. 6. This means that if PV installation capacity larger than maximum allowable power, the penetration impact becomes more severe and may lead to over voltage problem.

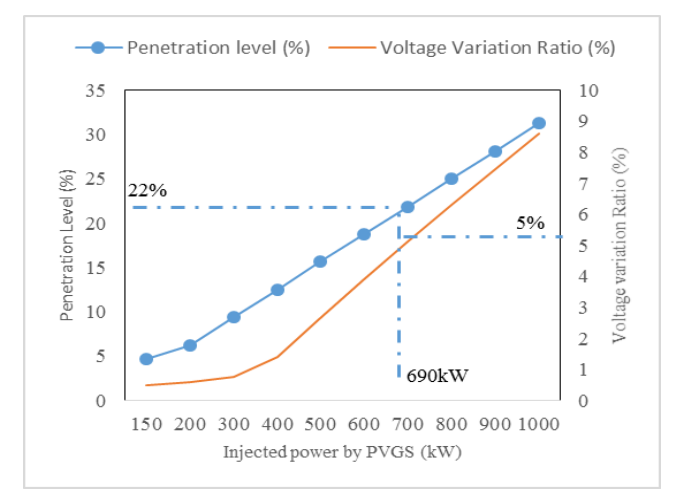

Fig. 6. VVR and PL verses the injected power of PV system. 
A sorting analysis of hourly weather data from Meteorology office in Kiribati was performed to derive the sunny and cloudy duration curve of solar irradiation analysis for different installed PV capacities, j. Fig. 8 and Fig. 9 shows a recorded solar irradiation with a simulated daily estimated PV generation for sunny and cloudy day respectively.

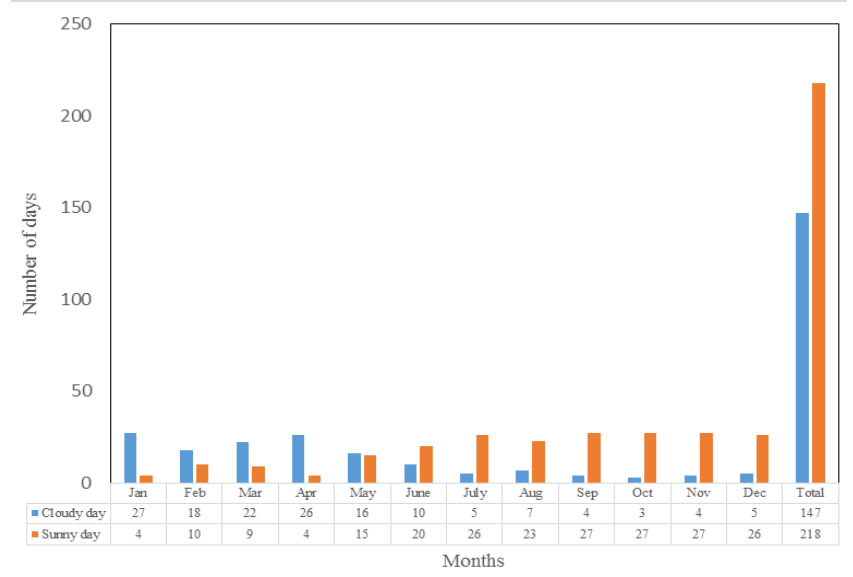

Fig. 7. Monthly number of cloudy and sunny for the year 2010 .

According to the weather information, a sunny day had sunshine duration of 13hours in March 2010. With this solar irradiation condition, it is found that the estimated generation power for a $690 \mathrm{kWp} \mathrm{PV}$ is increased with the solar irradiation by applied the model at (7-8). The maximum power generation is $530 \mathrm{~kW}$ and occurs at $12 \mathrm{hrs}$. Also, a cloudy day has low solar irradiation and the maximum PV power generation is $340 \mathrm{~kW}$ at $14: 30 \mathrm{pm}$. It is also found that the PV generation power fluctuates dramatically between 10:00am and 14:00pm due to the cloudy effect during the daytime period. A historical weather data provided by Meteorology office in 2010 as presented in Fig. 7, it shows the monthly number of cloudy and sunny day respectively. Besides it also shows the total number of sunny and cloudy days i.e. $218\left(\mathrm{NSD}_{2010}\right)$ and $147\left(\mathrm{NCD}_{2010}\right)$ in a year respectively. In order to simplify the process of determining the annual PV power generation, it is assumed that all sunny days have the same sunny solar irradiation condition and all cloudy days have the same cloudy solar irradiation condition, throughout the year.

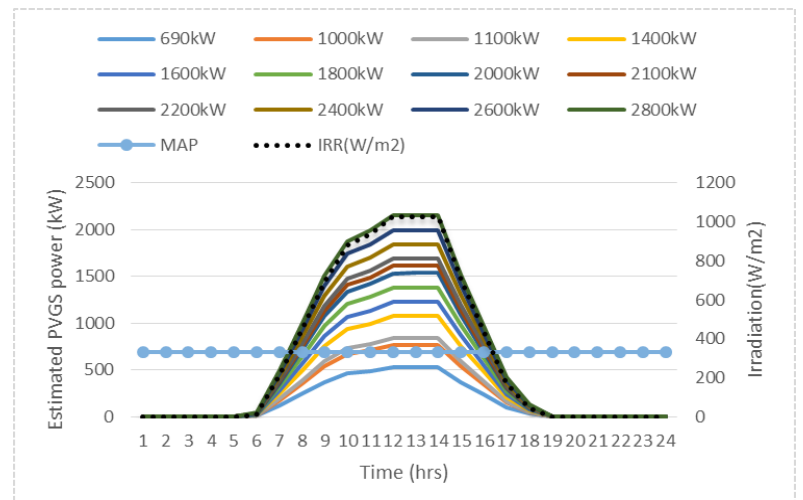

Fig. 8. Sunny day solar irradiance and estimated PV power generation for different PV sizes.

Fig. 8 and Fig. 9 show the hourly solar irradiation on March 2010 and the corresponding power generated by the PV system, which has a capacity ranging from $690 \mathrm{kWp}$ to $2800 \mathrm{kWp}$. In this PV system with an installed capacity of $690 \mathrm{kWp}$, the maximum power generation is $530 \mathrm{~kW}$ at $12 \mathrm{hrs}$. The load flow analysis of the study distribution feeder with $\mathrm{PV}$ power generation indicates that maximum PV power that can be injected without violating $\pm 5 \%$ voltage variation constraint is $690 \mathrm{~kW}$, which corresponds to an installation capacity of $860 \mathrm{kWp}$. Fig. 8 indicates the power generation should be curtailed when the PV installation capacity exceeds $1000 \mathrm{kWp}$.

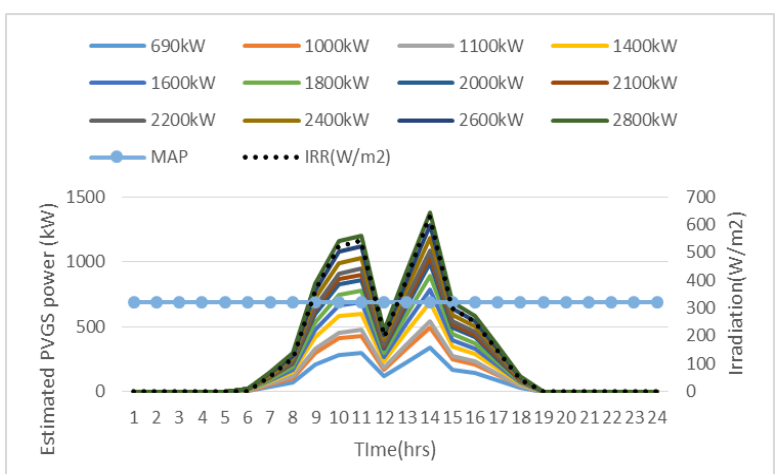

Fig. 9. Cloudy day solar irradiance and estimated PV power generation for different PV sizes.

\section{CASE STUdy-FInANCIAL ANALYSIS}

A financial analysis is performed to ensure that the feasibility of the system economic aspect. This is to figure out whether or not the capital investment cost of the PV system can be fully recovered from the allowed annual PV generation into the study feeder over the system life cycle. Table I shows the parameters used in this analysis. A project is considered to be financially feasible if the corresponding NPV is positive. The NPV of the investment can be calculated by (1).

\begin{tabular}{l|l}
\multicolumn{2}{c}{ TABLE I: PARAMETERS OF THE STUDY PV SYSTEM } \\
\hline Items & Parameters \\
\hline Life cycle & 26 years \\
O\&M cost (\%/year) & $5 \%$ \\
Installation de rating rate (\%/yr)-dr & $1.4 \%$ \\
Feed in tariff of PV (US $\$ / \mathrm{kWh)}$ & 0.4 \\
Present Worth Factor & 0.98 \\
Inflation rate (\%/yr)-g & $3 \%$ \\
\hline
\end{tabular}

Table II shows that the PV generation sold to the utility, energy curtailed, and the revenue generated by the PV system over a one-year period. When the feed in tariff of the study distribution feeder increases with the installation capacity but becomes saturated at the capacity exceeds $2800 \mathrm{~kW}$. However, curtailment of PV increases dramatically when PV installation capacity exceeds $4000 \mathrm{kWp}$.

For example, 1093MWh of solar energy can be harvested annually by the PV system of $690 \mathrm{kWp}$ capacity. When PV installation capacity is $1400 \mathrm{kWp}$, the PV generation of $0.4 \mathrm{c} / \mathrm{kWh}$ in Kiribati, the annual revenue of a PV system increases from $\$ 439,366$ (for $690 \mathrm{~kW}$ installed capacity) to $\$ 998,048$ (for $2800 \mathrm{~kW}$ installed capacity), when the proposed voltage control is applied to comply with the voltage regulation. 


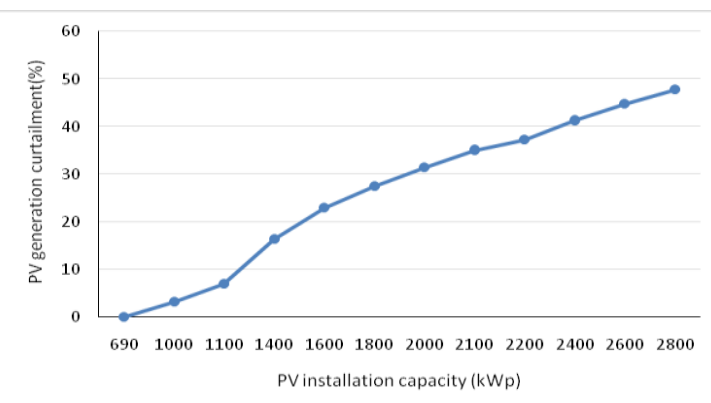

Fig. 10. Percentage of annual PV generation loss due to curtailment.

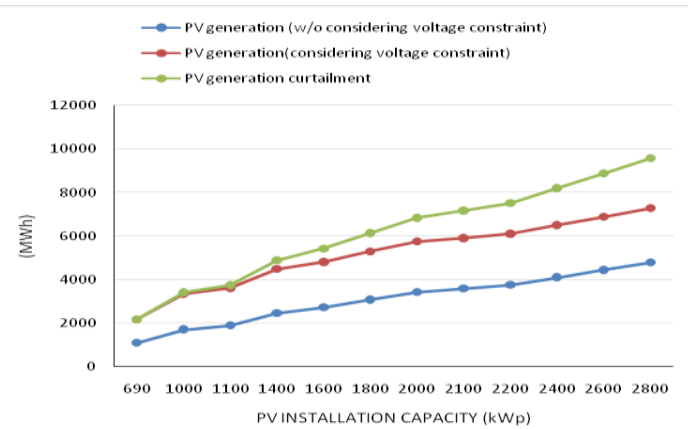

Fig. 11. Annual PV generation and amount of generation curtailment.

Fig. 11 shows the one year period PV generation with and without curtailment for various PV installation capacities. The total power that can be generated without considering voltage violations increase linearly with PV installation capacity. Partial PV generation has to be curtailed when the installation capacity exceeds $690 \mathrm{kWp}$ to prevent voltage violation at PCC. The PV generation that can be fed into annually by the PV system of $690 \mathrm{kWp}$ capacity. When PV installation capacity is $1400 \mathrm{kWp}$, the $\mathrm{PV}$ generation of 2046MWh can be sold to the distribution grid. This implies that $401 \mathrm{MWh}$ of PV generation must be rejected to prevent voltage violation, which is about $16 \%$ reduction of the total annual revenue as shown in Fig. 10. Here, this particular annual rejected PV generation reaches the threshold input power of the desalination plant (hourly: $45 \mathrm{~kW} / \mathrm{hr}$, yearly: 394MW/yr) which can produce $16.671 \mathrm{tr} / \mathrm{min}$.

\section{Net Present Value Method}

To perform the financial analysis to determine the optimal PV installation capacity by maximizing the NPV (1) of the study PV system with respect to different size of PV project assumed to be installed at bus 4 in Kiribati for computer simulation. The annual revenue of PV system is then calculated by multiplying with the PV energy generated by the feed in tariff. Based on these generated PV revenues, a financial analysis is performed to find out the optimal PV installation capacity due to the maximum NPV obtained.

To investigate the impact of power curtailment strategy to ensure the best cost effectiveness of PV projects, a financial analysis is performed to determine the PBY and NPV considering the cash flows over the system lifecycle.

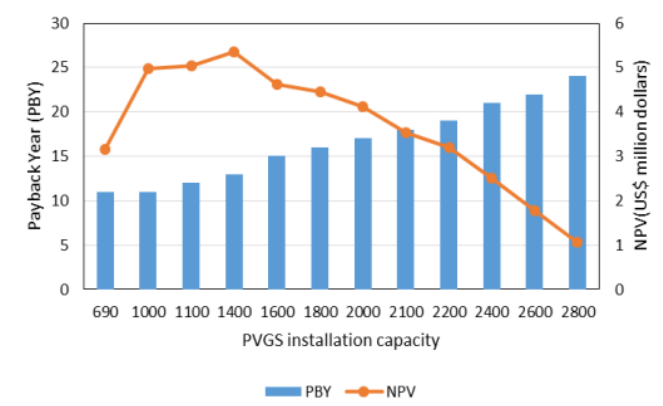

Fig. 12. Relationship of payback years and net present value (NPV) verses different PV sizes respectively.

Fig. 12 shows both the NPV and PBY obtained for the study PV system with various capacities when considering the financial parameters stated in table I. In this study, the optimal PV penetration level for the distribution feeder on a small island, the NPV approach considering the annual cash flows is applied. Because of the PV rejection energy, that leads to revenue loss, increases linearly with the PV installation capacity, therefore it becomes difficult to offset the increased PV investment cost. This can be seen in Fig. 12 when the PV installation capacity exceeds $1400 \mathrm{~kW}$ and then the NPV's decreases. The analysis shows that NPV increases with the penetration level and reaches the maximum value of 4.31million dollars, when PV installation capacity is $1400 \mathrm{kWp}$, and then NPV decreases as the PV capacity increases.

By letting NPV=0, the payback year of different PV capacities can be solved. When the curtailment applied, it is found that the optimal PV installation capacity's PBY is 13 years. And the trend has shown that the PBY is linearly increased with PV installation capacity. At the PV installation capacity of $2800 \mathrm{~kW}$, the PBY is 24 years which almost reaches the life end of the PV system i.e. 25 years. Although it will take long years to fully recover the investment cost of $2800 \mathrm{~kW}$ PV system, the project is still justified since its NPV is a positive value of around 1 million US dollar.

TABLE II: ANNUAL PV GENERATION AND CURTAILMENT FOR DIFFERENT PV SIZES

\begin{tabular}{|c|c|c|c|c|c|c|c|c|c|c|c|c|}
\hline PV capacity (MW) & 0.69 & 1 & 1.1 & 1.4 & 1.6 & 1.8 & 2 & 2.1 & 2.2 & 2.4 & 2.6 & 2.8 \\
\hline $\begin{array}{l}\text { PV generation allowed/sold } \\
\text { (MWh) }\end{array}$ & 1093 & 1653 & 1748 & 2046 & 2092 & 2228 & 2340 & 2327 & 2354 & 2405 & 2450 & 2495 \\
\hline $\begin{array}{l}\text { Sunny day curtailed PV } \\
\text { power }(\mathrm{MWh})\end{array}$ & 0 & 55 & 131 & 401 & 609 & 816 & 1031 & 1150 & 1270 & 1508 & 1747 & 1985 \\
\hline $\begin{array}{l}\text { Cloudy day curtailed PV } \\
\text { power }(\mathrm{MWh})\end{array}$ & 0 & 0 & 0 & 0 & 14 & 29 & 43 & 108 & 132 & 185 & 243 & 301 \\
\hline $\begin{array}{l}\text { Total curtailed } \\
\text { generation }(\mathrm{MWh})\end{array}$ & 0 & 55 & 131 & 401 & 623 & 845 & 1075 & 1258 & 1402 & 1693 & 1990 & 2286 \\
\hline $\begin{array}{l}\text { Net Revenue from absorbed } \\
\text { PV generation(US\$) }\end{array}$ & 437366 & 661095 & 699052 & 818236 & 836787 & 891184 & 936132 & 930909 & 941724 & 961804 & 979923 & 998043 \\
\hline $\begin{array}{l}\text { Revenue loss from rejected } \\
\text { PV generation }\end{array}$ & 0 & 21882 & 52223 & 160415 & 249294 & 338174 & 429822 & 503345 & 560825 & 677341 & 795817 & 914293 \\
\hline$\%$ Revenue loss & 0 & 3 & 7 & 16 & 23 & 28 & 31 & 35 & 37 & 41 & 45 & 48 \\
\hline
\end{tabular}




\section{CONCLUSION}

Various photovoltaic installation capacities have been analyzed both technically and economically on a small island distribution feeder to determine the optimal PV installation capacity by maximizing the NPV of the PV system over its life cycle. This paper has used the voltage control scheme adopted by power curtailment strategy to achieve the fully utilization of solar energy and to prevent the over voltage at the same time. A load flow simulation result shows that a maximum allowable power of $690 \mathrm{kWp}$ can fit well with power flow and voltage fluctuation of the grid. A PUB DNST feeder in Kiribati is selected for computer simulation. With a total power generated and the amount of PV energy curtailed over a one year period, a cash flow analysis is performed by considering the initial investment cost, O\&M and the revenue from the PV renewable energy which is calculated by multiplying the annual PV generation with the proposed feed in tariff of $0.4 \mathrm{c} / \mathrm{kW}$. With this proposed feed in tariff, the payback year has been solved as about 13 years for optimum PV size of $1400 \mathrm{~kW}$. This however generates a maximum NPV of around 5.62 million over its entire lifecycle and an estimated annual rejected generation capacity of around 401MWh. Here, the amount of annual rejected PV identified to be the potential energy for harvesting clean water on designated small islands at the rate of 16 liter $/ \mathrm{min}$.

\section{REFERENCES}

[1] C. S. Chen, C. T. Hsu, and R. Korimara, "The photovoltaic generation system impact on the energy demand of a small island and its financial analysis," Energy Procedia., vol. 14, pp. 411-417, 2012.

[2] R. Hara, H. Kita, T. Tanabe, H. Sugihara, A. Kuwayama, and S. Miwa, "Testing the technologies," Power and Energy Magazine, vol. 7, no. 3, pp. 77-85, May-June 2009.

[3] S. Morozumi, S. Kikuchi, Y. Chiba, J. Kishida, S. Uesaka, and Y. Arashiro, "Distribution technology development and demonstration projects in Japan," in Proc. Power and Energy Society General Meeting - Conversion and Delivery of Electrical Energy in the 21st Century, 2008 IEEE, 2008, pp. 1-7.

[4] W. Wongsaichua, W. J. Lee, S. Oraintara, K. Chiman, and F. Zhang, "Integrated high-speed intelligent utility tie unit for disbursed/renewable generation facilities," IEEE Transactions on Industry Applications, vol. 41, no. 2, pp. 507-513, March-April 2005.

[5] D. Menniti, A. Pinnarelli, and N. Sorrentino, "An hybrid PV-wind supply system with D-statcom interface for a water-lift station," in Proc. 2010 International Symposium on Power Electronics Electrical Drives Automation and Motion (SPEEDAM), June 14-16, 2010, pp. 1387-1392.

[6] L. Wang, T. H. Yeh, and W. J. Lee, and Z. Chen, "Analysis of a commercial wind farm in Taiwan part II: Different current-limit reactors and load tap changers on system performance," IEEE
Transactions on Industry Applications, vol. 47, no. 2, pp. 954-964, March-April 2011.

[7] M. R. Salem, L. A. Talat, and H. M. Soliman, "Voltage control by tap-changing transformers for a radial distribution network," IEE Proceedings Generation, Transmission and Distribution, vol. 144, no. 6, pp. 517-520, Nov. 1997.

[8] C. R. Chen and M. J. Lan, "Optimal demand response of Smart home with PV generators," International Journal of Photoenergy, 2014.

[9] MIT club North of California. (October 2015). [Online]. Available: https://www.youtube.com/watch?v=91GYrEk_PFE\&feature=em-subs _digest

[10] O. Gagrica, P. H. Nguyen, W. L. Kling, and T. Uhl, "Microinverter curtailment strategy for increasing photovoltaic penetration in low-voltage networks," IEEE Transactions on Sustainable Energy, vol. 6, no. 2, pp. 369-379, April 2015.

[11] R. Tonkoski, L. A. C. Lopes, and T. H. M. El-Fouly, "Coordinated active power curtailment of grid connected PV inverters for overvoltage prevention," IEEE Trans. Sustain. Energy, vol. 2, no. 2, pp. 139-147, 2011.

[12] Hitachi Brand Channel. (March 2014). Solution Hitachi solar power desalination in Abu Dabi. [Online]. Available: https://www.youtube.com/watch?v=NgXPooc7KmI

[13] C. H. Lin, W. L. Hsieh, C. S. Chen, T. T. Ku, and C. T. Tsai, "Financial analysis of a large scale photovoltaic system and its impact on distribution feeders," in Proc. 2010 IEEE Industry Applications Society Annual Meeting (IAS), 2010, pp. 1-8.

Cheng-Ting Hsu was born in Taiwan in 1963. He received the Ph.D. degrees in electrical engineering from National Sun Yat-Sen University, Taiwan, in 1995. He is currently a professor of electrical engineering at Southern Taiwan University of Science and Technology, Taiwan. His majors are computer control of power systems, smart grid, and renewable energy.

Roman Korimara was born in Kiribati in 1981. He received his master degree from National Sun Yat-Sen University, Taiwan, in 2011. He is currently working for the $\mathrm{Ph} . \mathrm{D}$. degree in electrical engineering at Southern Taiwan University of Science and Technology, Taiwan.

Tsun-Jen Cheng received a B.S.E.E. degree from National Chiao Tung University, Taiwan and an M.S.E.E. degree from Arizona State University, U.S.A. He is currently a lecturer at Southern Taiwan University of Science and Technology, Taiwan.

Lian-Jou Tsai was born in Taiwan in 1958. He received the Ph.D. degree in electrical engineering from National Cheng Kung University, Taiwan, in 1998. He is currently an associate professor of electrical engineering at Southern Taiwan University of Science and Technology, Taiwan. His majors are embedded system design and embedded operating systems.

Hung-Ming Huang was born in Taiwan in 1961. He received the Ph.D degree in electrical engineering from National Taiwan University, Taiwan, in 1995 . He is currently an associate professor of electrical engineering at Southern Taiwan University of Science and Technology, Taiwan. His majors are power system. 